\title{
Heat transfer performance for batch oscillatory flow mixing
}

\author{
G.G. Stephens ${ }^{1}$, M.R. Mackley * \\ University of Cambridge, Department of Chemical Engineering, Pembroke Street, Cambridge, CB2 3RA, UK
}

Received 28 January 2000; accepted 18 August 2001

\begin{abstract}
Experimental heat transfer data is presented for two batch operations of oscillatory flow mixing. In one case fluid is oscillated within a baffled tube and in the second case baffles are oscillated within a process fluid. For both situations the heat transfer coefficient depends on the intensity of oscillation, and the energy performance of each configuration corresponds to that of an equivalent net turbulent flow in a pipe or a batch stirred vessel. The results indicate that oscillatory flow batch mixing is as energy efficient as other conventional mixing configurations and the heat transfer performance indicates that each oscillatory flow mixing configuration could be satisfactorily used as a batch reactor system. (c) 2002 Elsevier Science Inc. All rights reserved.
\end{abstract}

Keywords: Oscillatory flow mixing; Heat transfer; Batch; Heat flux sensor; Fluid oscillation; Baffle oscillation

\section{Introduction}

This paper reports experimental heat transfer data obtained using two different experimental batch configurations and compares the data with previously reported results for continuous flow. The results are of potential relevance to both batch and continuous processing using this new type of mixing technology.

Oscillatory flow is a method of mixing materials using the combination of sharp edges (baffles) and a periodically reversing flow in a tube or channel, which has potential applications in several fields. Vortices generated on the downstream side of each baffle following each flow reversal interact with each other in a complex manner [1], known as oscillatory flow mixing. There is good global mixing within each inter-baffle region, with significant radial velocity components [2]. It is the oscillatory flow which controls the mixing and this is controlled by varying the frequency and amplitude of the oscillation: the mixing is therefore decoupled from any mean flow. The flow regime is turbulent in nature even with no net flow or with a net flow which would

\footnotetext{
${ }^{*}$ Corresponding author. Tel.: +44-1223-334784.

E-mail addresses: stepheng@bp.com (G.G. Stephens), mrm1@cheng.com.ec.uk (M.R. Mackley).

${ }^{1}$ Present address: BP Grangemouth, P.O. Box 21, Bo'ness Road, Grangemouth, Scotland, FK3 9XH, UK. Tel.: +44-1324-493172.
}

otherwise be laminar. This is one of the features of oscillatory flow mixing which clearly distinguishes it from the use of static mixer inserts, with which any improvement in radial mixing is affected by a mean flow.

An alternative method of producing a type of oscillatory flow is by oscillating the baffles. Baird and coworkers, for example, Baird and Rama Rao [3] have performed extensive work with oscillating baffle oscillatory flows, and Stonestreet [4] reported flow patterns for an oscillating baffle assembly similar to those of the fixed baffles oscillated fluid configuration.

Heat transfer data for an oscillatory flow mixer with a net throughput of liquid have been published by Mackley et al. [5] and Mackley and Stonestreet [6]. Mackley et al. [5] demonstrated that oscillatory flow with a net throughput displays a significant enhancement of tube heat transfer with respect to the same net throughput in a smooth tube with no oscillatory component; the oscillatory flow and baffles both had to be present to produce this effect. Mackley and Stonestreet [6] reported up to thirty-fold increases in tube side Nusselt numbers. Nusselt numbers more typical of fully turbulent flows could be achieved with oscillatory flows where the net throughput had a Reynolds number of only 100 .

Oscillatory flow offers advantages to continuous mixing processes. It is suitable, for example, for production processes which require a long residence time but nevertheless require careful temperature control. A 


\begin{tabular}{|c|c|c|c|}
\hline Nomenclature & & $T_{\mathrm{i}}$ & initial tube-side temperature \\
\hline$A$ & area of heat transfer surface & & $\left({ }^{\circ} \mathrm{C}\right)$ \\
\hline & $\left(\mathrm{m}^{2}\right)$ & $T_{\mathrm{w}}$ & shell-side fluid temperature $\left({ }^{\circ} \mathrm{C}\right)$ \\
\hline$C_{\mathrm{p}}$ & specific heat capacity of & $T_{\text {wall }}$ & wall temperature $\left({ }^{\circ} \mathrm{C}\right)$ \\
\hline & tube-side fluid $(\mathrm{J} /(\mathrm{kg} \mathrm{K}))$ & $T_{1}, T_{2}$ & two different temperatures (Fig. \\
\hline $\mathrm{CR}$ & baffle constriction ratio & & 2) $\left({ }^{\circ} \mathrm{C}\right)$ \\
\hline & (dimensionless) & $t$ & elapsed time (s) \\
\hline$D$ & impeller diameter $(\mathrm{m})$ & $u$ & superficial net velocity of fluid \\
\hline$D_{\mathrm{t}}$ & tube diameter $(\mathrm{m})$ & & $(\mathrm{m} / \mathrm{s})$ \\
\hline$f$ & oscillatory frequency $(\mathrm{Hz})$ & $V_{\max }$ & peak oscillatory velocity $(\mathrm{m} / \mathrm{s})$ \\
\hline$h$ & $\begin{array}{l}\text { overall heat transfer } \\
\text { coefficient }\left(\mathrm{W} /\left(\mathrm{m}^{2} \mathrm{~K}\right)\right)\end{array}$ & $x_{\mathrm{o}}$ & $\begin{array}{l}\text { oscillatory amplitude (centre to } \\
\text { peak) (m) }\end{array}$ \\
\hline$h_{\mathrm{s}}$ & $\begin{array}{l}\text { shell-side heat transfer } \\
\text { coefficient }\left(\mathrm{W} /\left(\mathrm{m}^{2} \mathrm{~K}\right)\right)\end{array}$ & Greek letters & \\
\hline$h_{\mathrm{t}}$ & $\begin{array}{l}\text { tube-side heat transfer } \\
\text { coefficient }\left(\mathrm{W} /\left(\mathrm{m}^{2} \mathrm{~K}\right)\right)\end{array}$ & $\begin{array}{l}\mu \\
\mu_{\mathrm{w}}\end{array}$ & $\begin{array}{l}\text { viscosity of process fluid ( } \mathrm{Pa} \mathrm{s} \text { ) } \\
\text { fluid viscosity at wall }\end{array}$ \\
\hline$k_{\mathrm{t}}$ & $\begin{array}{l}\text { conductivity of process liquid } \\
(\mathrm{W} /(\mathrm{m} \mathrm{K}))\end{array}$ & $v$ & kinematic viscosity $\left(\mathrm{m}^{2} / \mathrm{s}\right)$ \\
\hline$k_{\mathrm{w}}$ & conductivity of tube wall & Dimensionless groups & \\
\hline$m$ & $\begin{array}{l}(\mathrm{W} /(\mathrm{m} \mathrm{K})) \\
\text { mass of fluid in tube which is } \\
\text { being cooled }(\mathrm{kg})\end{array}$ & $\begin{array}{l}N u_{\mathrm{str}} \\
N u_{\mathrm{t}}=\frac{h_{\mathrm{t}} D_{\mathrm{t}}}{k_{\mathrm{t}}} \\
\operatorname{Pr}=\frac{\mu \mathrm{C}_{\mathrm{t}}}{k}\end{array}$ & $\begin{array}{l}\text { stirred tank Nusselt number } \\
\text { tube-side Nusselt number } \\
\text { Prandtl number }\end{array}$ \\
\hline$N$ & stirrer speed (rev/s) & $\operatorname{Re}_{\mathrm{imp}} \frac{N D_{\mathrm{imp}}^{2}}{v}=\frac{\rho_{c} N D_{\mathrm{imp}}^{2}}{\mu}$ & impeller Reynolds number \\
\hline $\begin{array}{l}q \\
r_{\mathrm{i}}\end{array}$ & $\begin{array}{l}\text { heat flux }\left(\mathrm{W} / \mathrm{m}^{2}\right) \\
\text { inner radius of tube wall (m) }\end{array}$ & $R e_{\mathrm{net}}=\frac{u D_{t}}{v_{c}}$ & net flow Reynolds number \\
\hline $\begin{array}{l}r_{\mathrm{o}} \\
T\end{array}$ & $\begin{array}{l}\text { outer radius of tube wall }(\mathrm{m}) \\
\text { time-varying temperature of } \\
\text { tube-side fluid }\left({ }^{\circ} \mathrm{C}\right)\end{array}$ & $\begin{array}{l}R e_{\text {osc }}=\frac{2 \pi f x_{0} D_{t}}{v_{c}} \\
S t=\frac{D_{t}}{4 \pi x_{0}} \\
V i=\frac{\mu}{\mu_{\mathrm{w}}}\end{array}$ & $\begin{array}{l}\text { oscillatory Reynolds number } \\
\text { Strouhal number } \\
\text { viscosity ratio }\end{array}$ \\
\hline
\end{tabular}

low bulk flow velocity permits a smaller mixer but the heat transfer can be controlled independently through the oscillatory conditions.

Oscillatory flow may also offer advantages to batch mixing processes which require uniform controllable mixing throughout the vessel and good temperature control. One example is suspension polymerisation in which a particular size distribution of the polymer product may be obtained by controlling the mixing conditions [7]. Good temperature control is required to control the exothermic reaction as well as product properties such as the molecular weight distribution. However no heat transfer data have yet been published for oscillatory flow mixing in batch node. Clearly there is a need for batch mode oscillatory flow heat transfer data.

This paper presents heat transfer data obtained from two oscillatory flow mixers operating in batch mode. The first configuration uses the fluid oscillation method in which the baffles remain stationary while the fluid is oscillated by pistons, whereas the second configuration employs oscillating baffles. The data obtained from the two systems are compared with each other, and with the data of Mackley and Stonestreet [6] extrapolated to the condition of zero net flow. The heat transfer performance of batch oscillatory flow mixing is then compared with that of the standard stirred tank, since the stirred tank can also be used as a batch mixer in which turbulent conditions can be generated, and it is the conventional reactor for suspension polymerisation reactions, an intended use for the batch oscillatory flow mixer.

Oscillatory flows in batch mode can be characterised by two parameters. The first is the oscillatory Reynolds number, given as

$\operatorname{Re}_{\mathrm{osc}}=\frac{2 \pi f x_{\mathrm{o}} D_{\mathrm{t}}}{v}$,

where $f$ is the frequency of oscillation, $x_{\mathrm{o}}$ is the centre to peak amplitude of oscillation (equal to half the stroke), and $D_{\mathrm{t}}$ is the tube diameter. The second parameter is the Strouhal number

$S t=\frac{D_{\mathrm{t}}}{4 \pi x_{\mathrm{o}}}$.

The Strouhal number describes the effects of the oscillatory amplitude and varies with inverse proportion to it.

If the oscillatory flow mixer is operating in continuous mode then a net flow Reynolds number must also be used to describe the net throughput:

$R e_{\text {net }}=\frac{u D_{\mathrm{t}}}{v}$,

where $u$ is the superficial net velocity of the fluid. 
The geometry of the baffles can be described by a constriction ratio (CR) where

$\mathrm{CR}=\frac{\text { cross-section of tube obstructed by baffle }}{\text { total cross-sectional area of the tube }}$.

\section{Heat transfer equipment}

\subsection{Experimental configuration 1: Oscillated fluid exper- iments}

Data have been obtained for heat transfer from an oscillated fluid contained within a jacketed tube with fixed baffles. For a shell and tube heat exchanger, where a fixed mass of fluid in the tube is cooled (or heated) by the flow of a fluid of constant temperature through the shell, the tube-side Nusselt number can be obtained from an analysis of the variation of the temperature of the fluid in the tube.

A non-steady state heat balance for a fixed mass of fluid in a tube gives

$\frac{A h t}{m C_{\mathrm{p}}}=\ln \left(\frac{T_{\mathrm{i}}-T_{\mathrm{w}}}{T-T_{\mathrm{w}}}\right)$,

where $m$ is the mass of fluid in the tube which is being cooled, $A$ is the area of the heat transfer surface, $C_{\mathrm{p}}$ is the specific heat capacity of the tube-side fluid, $h$ is the overall heat transfer coefficient for the system, $T$ is the time varying temperature of the tube-side fluid, $T_{\mathrm{i}}$ is the initial tube-side temperature, $T_{\mathrm{w}}$ is the temperature of the shell-side fluid which remains constant, and $t$ is the elapsed time. This can be rearranged to

$\ln \left(T-T_{\mathrm{w}}\right)=-\frac{A h t}{m C_{\mathrm{p}}}+\ln \left(T_{\mathrm{i}}-T_{\mathrm{w}}\right)$.

It can be seen that a graph of $-\ln \left(T-T_{\mathrm{w}}\right)$ against $t$ should give a straight line of slope $A h / m C_{\mathrm{p}}$ and intercept $-\ln \left(T_{\mathrm{i}}-T_{\mathrm{w}}\right)$. The overall heat transfer coefficient can then be determined from the slope of the graph.

The overall heat transfer coefficient contains contributions from the shell-side heat transfer coefficient, the coefficient due to heat transfer across the wall separating the tube and the shell, and the tube-side heat transfer coefficient. This relation is given by

$\frac{1}{h}=\frac{1}{h_{\mathrm{t}}}+\frac{r_{\mathrm{i}} \ln \left(r_{\mathrm{o}} / r_{\mathrm{i}}\right)}{k_{\mathrm{w}}}+\frac{r_{\mathrm{i}}}{r_{\mathrm{o}} h_{\mathrm{s}}}$,

where $h_{\mathrm{t}}$ is the tube-side heat transfer coefficient, $h_{\mathrm{s}}$ is the shell-side heat transfer coefficient, $k_{\mathrm{w}}$ is the conductivity of the tube wall, and $r_{\mathrm{i}}$ and $r_{\mathrm{o}}$ are the inner and outer radii of the tube wall curvature, respectively. For the equation to be used in this form, the overall heat transfer coefficient must be related to the inner radius of the tube wall curvature, so the heat transfer area term should refer to the area of the inside of the tube wall.
The tube-side heat transfer coefficient can then be determined.

The tube-side Nusselt number can then be determined from

$N u_{\mathrm{t}}=\frac{h_{\mathrm{t}} D_{\mathrm{i}}}{k_{\mathrm{t}}}$,

where $k_{\mathrm{t}}$ is the conductivity of the fluid in the tube.

Batch heat transfer experiments were performed in a vertically mounted, stainless steel u-tube (see Fig. 1). The two vertical sections were jacketed while the top section joining the two vertical limbs was well insulated. Each of the two jacketed sections were $1.16 \mathrm{~m}$ in length, and $24 \mathrm{~mm}$ inside diameter. The tube wall was $0.7 \mathrm{~mm}$ thick with a conductivity of $16 \mathrm{~W} \mathrm{~m}^{-1} \mathrm{~K}^{-1}$. The two straight sections were independently jacketed, giving an area for heat transfer of $0.0875 \mathrm{~m}^{2}$ for each straight limb. Stationary baffle arrangements consisting of 24 $\mathrm{mm}$ discs, connected together by thin steel rods, with single $12 \mathrm{~mm}$ orifices, giving a $75 \% \mathrm{CR}$ were used in the tube; the baffles were designed to give a "push fit". Baffles were also fitted in the shell: helical baffles were used to ensure that the shell-side heat transfer coefficient would not be limiting.

The apparatus used was originally designed for an investigation of heat transfer in oscillatory flow with a

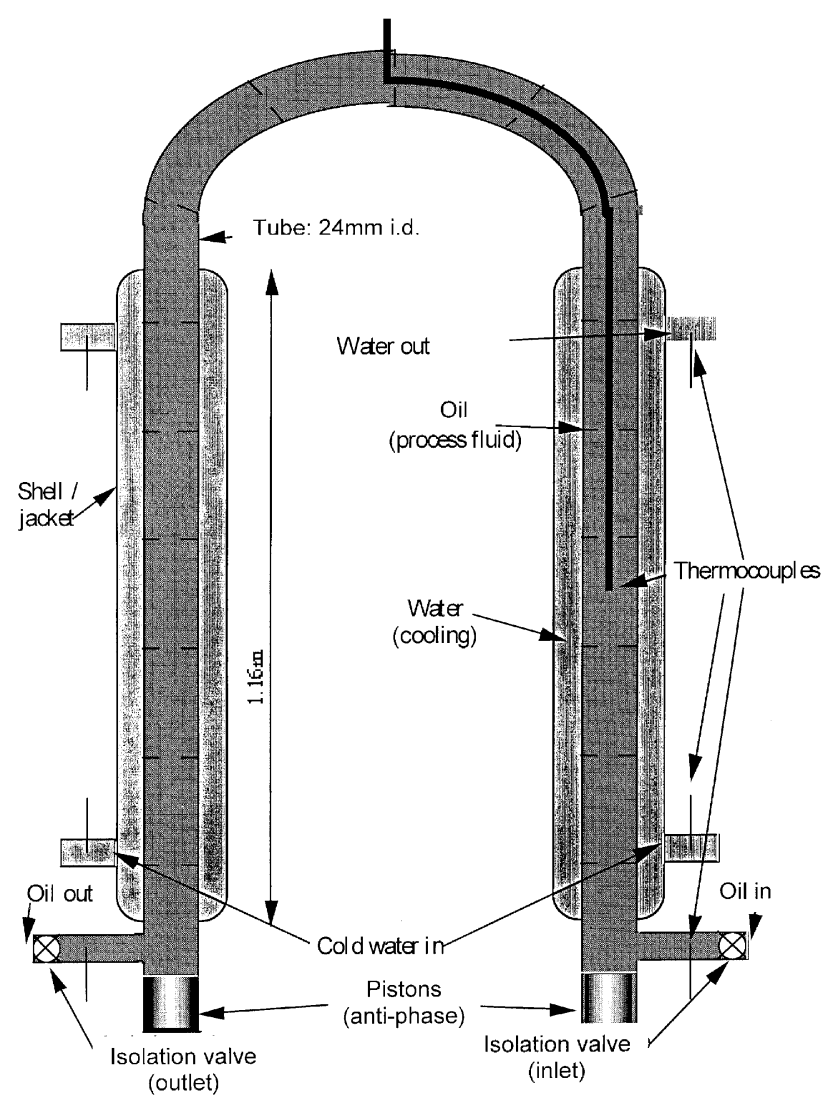

Fig. 1. Configuration 1: The u-tube used for heat transfer experiments. The tube contains single orifice baffles, with a $75 \% \mathrm{CR}$, at a spacing of 1.5 tube diameters. 
net throughput. It was used in this work because it was already instrumented for heat transfer measurements and could be adapted to operate in batch mode with few changes. The design allows the tube to be easily filled with hot oil at a uniform temperature. In addition, the apparatus was similar in design to the rig used by Mackley and Stonestreet [6], allowing comparisons with their data. Had a new rig been constructed, a single vertical tube would have avoided any problems with the unjacketed top section.

The oscillation was provided by pistons at the lower ends of each of the straight sections, the pistons being driven by rotating cams operating in anti-phase. The piston seals consisted of carbon-impregnated graphite glyde rings, energised by viton o-rings, with a wiper on the top of the piston. The amplitude and frequency of the oscillation were controlled electronically. The amplitude could be set to a precision of $\pm 0.5 \mathrm{~mm}$ and the frequency to $\pm 0.1 \mathrm{~Hz}[8]$.

The shell-side fluid was tap water at mains pressure. The process fluid used in the tube-side was a mineral oil, Shell Tellus R10. With this arrangement the shell-side does not limit heat transfer. The oil is a Newtonian fluid, whose density was estimated as $840 \mathrm{~kg} \mathrm{~m}^{-3}$ and viscosity as $0.007 \mathrm{~Pa}$ s, both being appropriate averages over the range of temperatures used in this work. The specific heat capacity of the oil was $2000 \mathrm{~J} \mathrm{~kg}^{-1} \mathrm{~K}^{-1}$, and its conductivity was $0.137 \mathrm{~W} \mathrm{~m}^{-1} \mathrm{~K}^{-1}$. The mass of oil in each straight limb of the vessel was $0.441 \mathrm{~kg}$.

The oil temperature was monitored by a K-type thermocouple positioned at the centre of one of the straight sections of the u-tube, by a thermocouple located at the tube filling point, and by a thermocouple at the tube outlet. The water temperature was monitored at the inlet and outlet of the shell of that straight section. (All the thermocouples were calibrated before the start of the work.) The analogue output from the thermocouples was digitally displayed for operator temperature monitoring, and was also fed to an analogue-to-digitalconverter (ADC) and thence to an IBM compatible 486 computer for further analysis. The accuracy of temperature measurements with this equipment is described by Mackley and Stonestreet [6].

\subsection{Experimental configuration 2: Oscillating baffle experiments}

The apparatus used to obtain heat transfer data for oscillatory flow mixing with oscillated baffles was designed for use as a suspension polymerisation reactor, for which a jacketed glass vessel was found to be optimal (see Fig. 2). The process fluid, contained in the vessel was agitated by oscillating baffles whilst, as in the above section, its temperature was controlled by a second fluid circulating in the shell. However, the glass wall between the vessel and the shell, $3 \mathrm{~mm}$ in thickness, had a heat

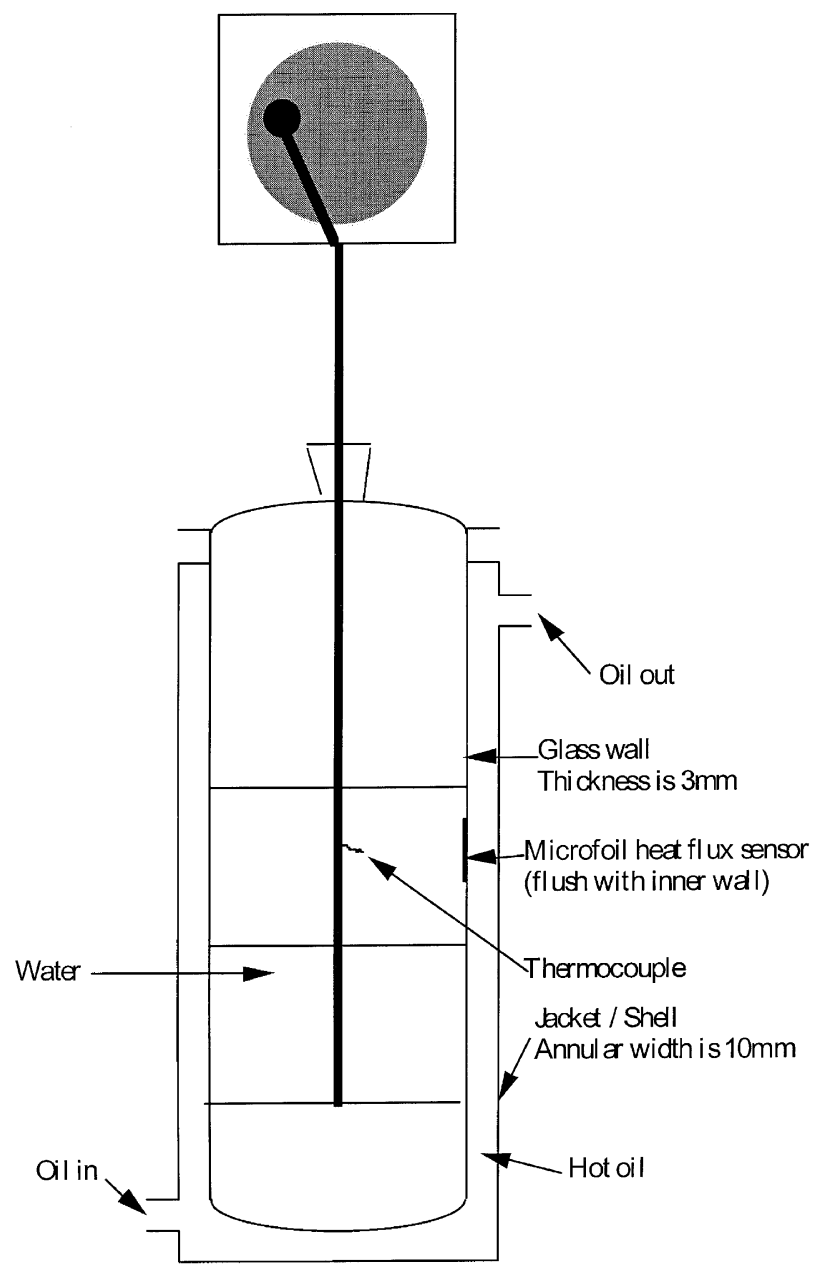

Fig. 2. Configuration 2: The "oscillating baffle" rig used for heat transfer experiments.

transfer resistance significantly larger than the mixer used above. This resistance would have masked any variations in the tube-side heat transfer coefficient had the experimental design used in the previous section been adopted. A method of directly measuring the tubeside heat transfer coefficient without reference to the overall heat transfer coefficient was therefore required.

The tube-side heat transfer coefficient $h_{\mathrm{t}}$ is given by the heat flow per unit are (the heat flux $q$ ) from the tubeside fluid to the wall divided by the temperature difference between the fluid and the wall:

$h_{\mathrm{t}}=\frac{q}{T_{\text {wall }}-T}$.

The tube-side Nusselt number can then be determined as before:

$N u_{\mathrm{t}}=\frac{h_{\mathrm{t}} D_{\mathrm{i}}}{k_{\mathrm{t}}}$.

A microfoil heat flux sensor, supplied by Rhopoint was fixed to the inside of the tube wall. This measured the heat flux $q$ from the fluid to the wall, and the wall temperature $T_{\text {wall }}$. A K-type thermocouple measured the 
temperature of the fluid $T$. The tube-side heat transfer coefficient could then be directly calculated, independently of the shell or wall heat transfer resistances. If these other resistances are low, the heat flux $q$ will be high and the tube-side temperature difference $T_{\text {wall }}-T$ will also be high. Conversely if the other heat transfer resistances are high, the heat flux will be low and the tube-side temperature difference will be low. The tubeside heat transfer coefficient $h_{\mathrm{t}}$, however remains unchanged since it is the ratio of the heat flux and the tube-side temperature difference, and is determined by the fluid mechanics in the tube, regardless of the wall or the shell. Each set of $q$ and $T_{\text {wall }}-T$ values allows an additional determination of $h_{\mathrm{t}}$. With a high sampling rate, multiple determinations of $h_{\mathrm{t}}$ are possible.

Such heat flux sensors have also been used by Mohan et al. [9], Jones and Ward [10] and Davies and Henstridge [11]. The sensor monitors the temperature difference across a thermal barrier by means of thermoelectric junctions on either side of the barrier. This temperature difference is then converted to the heat flux, taking into account the thermal resistance of the barrier [12]. The sensor is thin $(0.1 \mathrm{~mm})$ with a very low heat capacity and a very high conductivity to ensure a fast response time of $0.06 \mathrm{~s}$, a very small contribution to the tube-side heat transfer resistance, and very little disruption to the vessel's fluid mechanics. The measured heat flux is precise to $\pm 5 \%$.

A T-type thermocouple embedded in the sensor monitored the temperature of the inner surface of the tube wall. The output of this thermocouple was fed to a $\mathrm{K}$-type digital display to give an output to a precision of $0.1^{\circ} \mathrm{C}$. Calibration tests showed this arrangement to be reliable.

A round bottom glass vessel, $75 \mathrm{~mm}$ in diameter and filled to a depth of about $270 \mathrm{~mm}$ was used, as shown in Fig. 2, the vessel dimensions being optimised for further use as a suspension polymerisation reactor. Stainless steel baffles, $73 \mathrm{~mm}$ in diameter, connected by a central steel rod were used. The central rod was connected via a crank to a motor driven wheel and positioned by a PTFE guide in the vessel's lid, in order to oscillate the baffles vertically. The amplitude of oscillation could be set with a precision of $\pm 0.5 \mathrm{~mm}$ and the frequency with a precision of $\pm 0.25 \mathrm{~Hz}$. A $1 \mathrm{~mm}$ gap between the baffles and the vessel's glass wall was maintained in order to reduce the risk of the steel baffles scratching the glass. The baffles were thin discs at a spacing of $70 \mathrm{~mm}$, with three $15 \mathrm{~mm}$ diameter orifices in each disk, see Fig. 3. Holes in adjacent plates were off-set.

The process fluid in the tube was water, since water is the major component in a suspension polymerisation mixture and the vessel was intended for use as a suspension polymerisation reactor. The conductivity of water was taken to be $0.65 \mathrm{~W} \mathrm{~m}^{-1} \mathrm{~K}^{-1}$. The temperature control fluid was the mineral oil Shell Tellus R10,

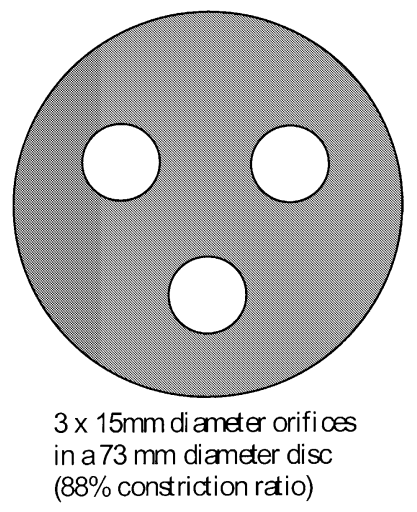

Fig. 3. Configuration 2: The baffle plate used in the oscillating baffle heat transfer investigation.

circulated through the shell by a Connair Churchill heater-cooler-pump. The inclusion of a cooling facility with this pump allowed the oil to be cooled between each experiment. This arrangement was used since it was the same configuration as would be used in the subsequent use of the vessel as a suspension polymerisation reactor and so allowed determination of the heat transfer that would be achieved in that configuration. Although the tube-side heat transfer would not be limiting in this configuration, the use of the heat transfer probe allowed it to be determined independently of the other heat transfer resistances.

The microfoil heat sensor was fixed to the inner surface of the tube wall, at a liquid depth of $70 \mathrm{~mm}$, using an adhesive which forms a uniform film $0.05 \mathrm{~mm}$ thick [12] between the sensor and the wall, and therefore presents very low thermal resistance. To measure the temperature of the process fluid, a K-type thermocouple was fixed to the baffle assembly, so that its depth at the mid-point of the oscillatory cycle was also $70 \mathrm{~mm}$. The thermocouple probe was not in contact with the baffle assembly. The output from the sensor and the thermocouples was fed to an ADC and hence to an IBM compatible PC for data logging and further analysis. All the thermocouples were calibrated before the start of the work.

\section{Visualisation of oscillatory flow mixing}

Flow visualisation images give a qualitative picture of oscillatory flow mixing. Such images have been obtained for both methods of oscillatory flow.

\subsection{Configuration 1: Oscillated fluid}

For the oscillated fluid method, a vertical perspex tube $1 \mathrm{~m}$ in height with the same internal geometry as the mixer used in the heat transfer investigation was used. A visualisation box was mounted around a section of the tube about half way up the height of the tube; this box presented a planar section to the camera, 
minimising any effects of refraction caused by the large curvature of the tube. A plane beam of illumination, approximately $1 \mathrm{~mm}$ in thickness, was provided by a mercury vapour lamp, and the flow pattern images were obtained by still photography using $35 \mathrm{~mm}$ film in a Contax camera with an exposure time of one thirtieth of a second, and an aperture step of F-8, in order to obtain streaklines showing the fluid motion.

The fluid in the tube was water, seeded with polyethylene particles with diameters between 180 and 320 $\mu \mathrm{m}$, dispersed with the aid of a wetting agent. The density of the particles was close to that of the water. The particles were therefore neutrally buoyant so their motion was representative of the fluid motion.

Fluid oscillation was provided by an electro-mechanical oscillator, controlled by a signal generator, and transmitted by means of a piston and diaphragm to the fluid in the tube; the oscillation was monitored by an oscilloscope.

Fig. 4 shows flow patterns obtained at an oscillatory Reynolds number of 450 and a Strouhal number of 1.9, a frequency of $3 \mathrm{~Hz}$ and a centre to peak amplitude of 1 $\mathrm{mm}$. These values are in the middle of the operating range for this apparatus.

$R e_{\mathrm{osc}}=\frac{2 \pi f x_{\mathrm{o}} D_{\mathrm{t}}}{v}=\frac{2 \times \pi \times 3 \times 0.001 \times 0.024}{10^{-6}}=450$,

$S t=\frac{D_{\mathrm{t}}}{4 \pi x_{\mathrm{o}}}=\frac{0.024}{4 \times \pi \times 0.001}=1.9$.

Fluid below the baffles is passing through the baffles and vortices are being generated downstream (above) of the baffles. The photograph was not taken at a specific point in the oscillatory cycle, but visual observation of the flow patterns confirmed that the level of fluid motion visible is representative of the fluid motion in the tube. A complex time dependent flow is observed with good radial and axial mixing evident from the fluid motion, which is of uniform intensity throughout the inter-baffle region. The apparent stagnant region below the baffle is deceptive. There might be no flow beneath the baffle at the point in the oscillatory cycle when the photograph was taken, but the time-dependent nature of the flow means that at a later point in the cycle, the vortices seen above the baffle will be seen below the baffle. The mechanisms of vortex generation, growth and interaction are visible; these are the basic mechanisms of oscillatory flow mixing [1]. It can also be inferred that a stretch and fold mechanism is operating, with elements of fluid being stretched as they are accelerated towards the baffles in regions of extensional flow, and folded in the regions of vorticity beyond the baffles.

\subsection{Configuration 2: Oscillating baffles}

For the oscillating baffle system, a single wall version of the oscillating baffle reactor was used. The fluid in the

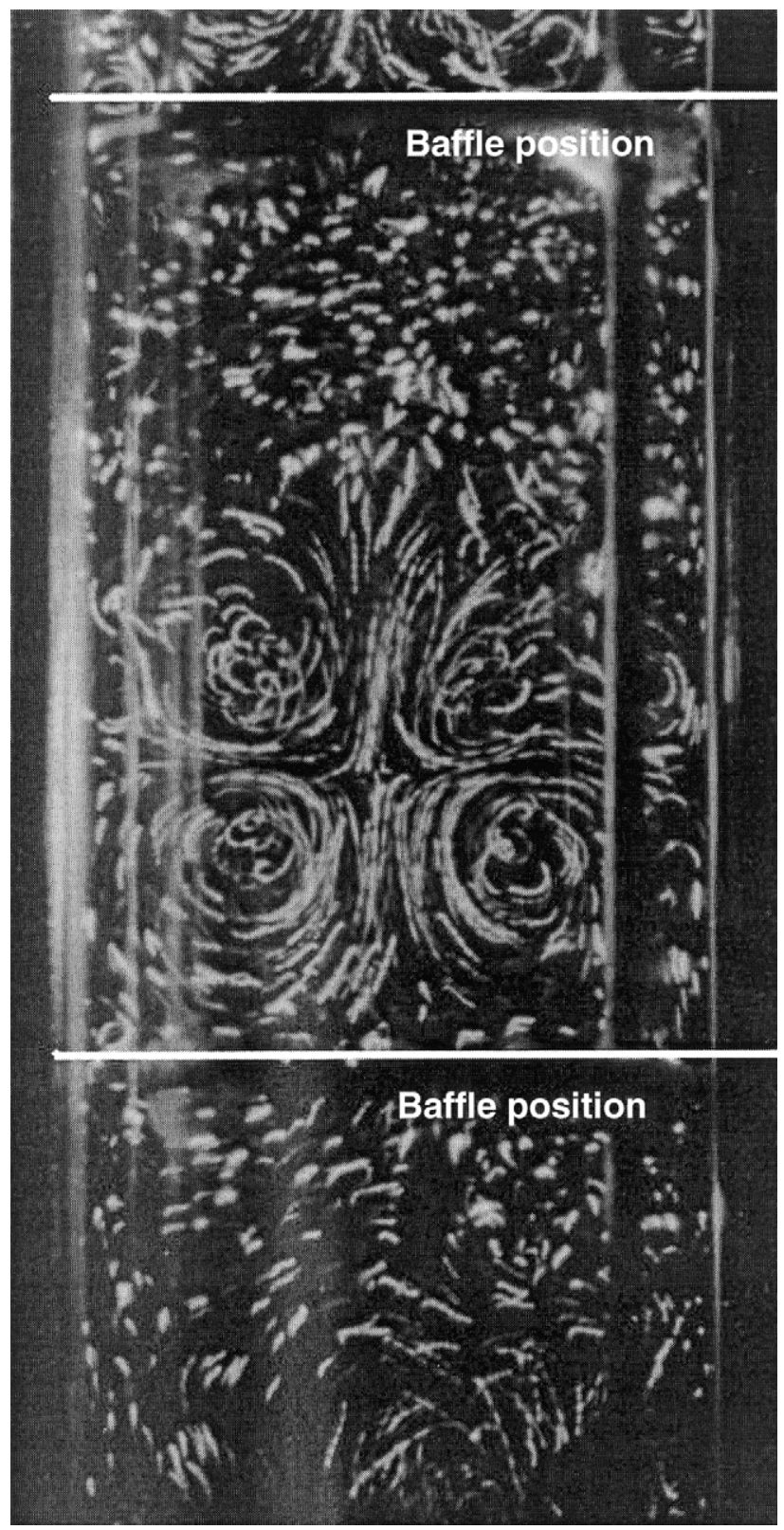

Fig. 4. Configuration 1: Flow patterns in a $24 \mathrm{~mm}$ i.d. tube with oscillated fluid. $R e_{\mathrm{o}}=450, S t=1.9\left(x_{\mathrm{o}}=1 \mathrm{~mm}, f=3 \mathrm{~Hz}\right)$.

vessel was water, seeded as in the above section, with the same seeding density in all the images shown in this section. A plane beam of illumination was again provided by a mercury vapour lamp. The fluid flow patterns were followed by video, using a Panasonic S-VHS camera at a frame rate of 50 frames per second and a shutter speed of one fiftieth of a second, with a hard copy image obtained from a video printer.

Fig. 5 shows the flow patterns at an oscillatory Reynolds number of 23,600 and a Strouhal number of 0.6 , a frequency of $5 \mathrm{~Hz}$ and a centre to peak amplitude of $10 \mathrm{~mm}$. These values are in the middle of the operating range for this vessel and are typical of the 

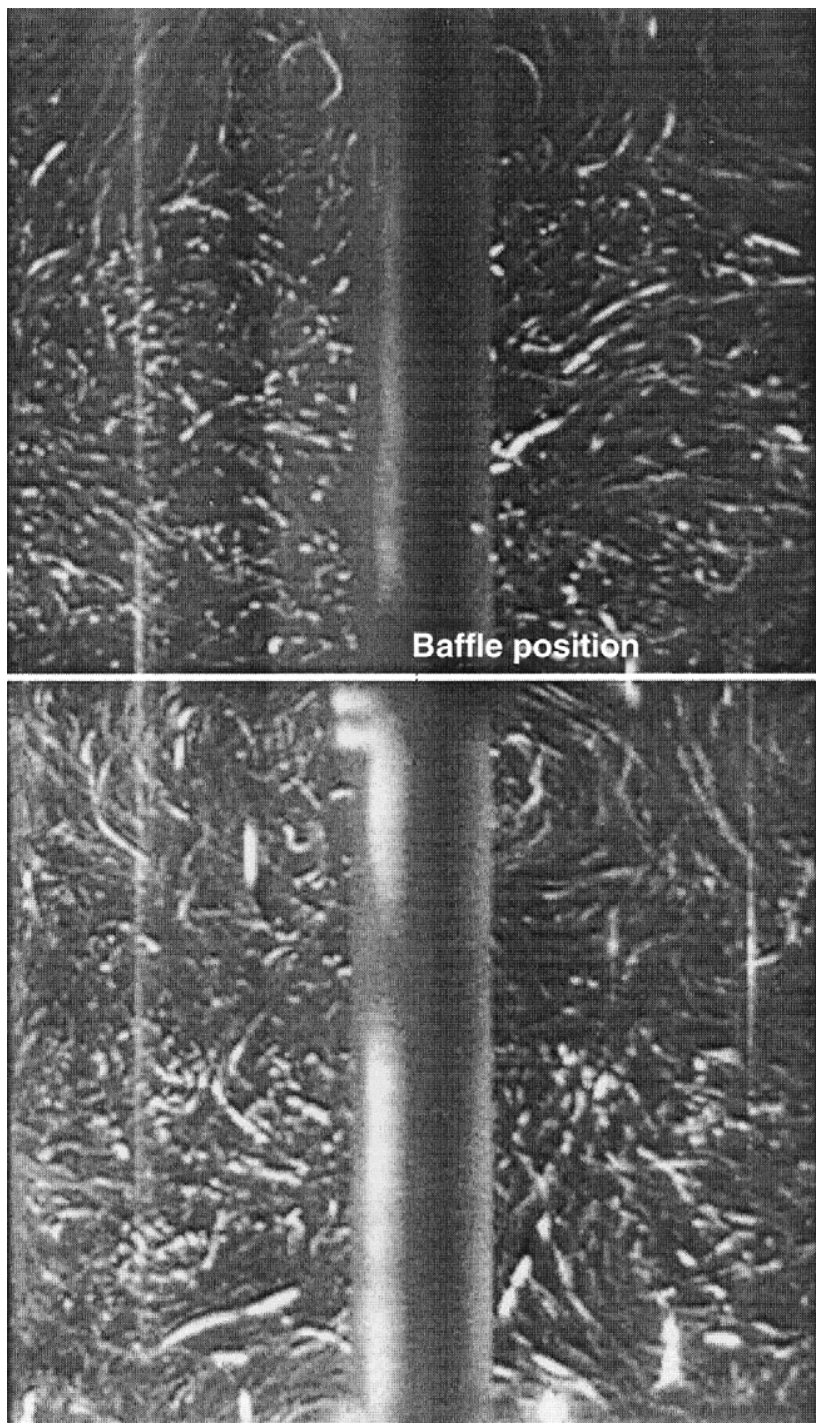

Fig. 5. Configuration 2: Flow patterns in a $75 \mathrm{~mm}$ i.d. tube with oscillating baffles. $R e_{\mathrm{o}}=23,600 \mathrm{St}=0.6\left(x_{\mathrm{o}}=10 \mathrm{~mm}, f=5 \mathrm{~Hz}\right)$.

operating conditions subsequently used for suspension polymerisation reactions.

$R e_{\mathrm{osc}}=\frac{2 \pi f x_{\mathrm{o}} D_{\mathrm{t}}}{v}=\frac{2 \times \pi \times 5 \times 0.01 \times 0.075}{10^{-6}}=23,600$,

$S t=\frac{D_{\mathrm{t}}}{4 \pi x_{\mathrm{o}}}=\frac{0.075}{4 \times \pi \times 0.01}=0.6$.

The video frame presented corresponds to the point of maximum downwards baffle velocity, at which the baffles are at their central position and their acceleration is zero. Vortices can be seen immediately downstream (below) of the baffles and also elsewhere in the tube. Vortices form and then move into the mainstream, so the mixing mechanism is similar to that of oscillatory flow with fixed baffles. Oscillating the baffles in a fluid filled tube is therefore a valid method for producing oscillatory flow, and can be expected to possess similar process advantages to its fixed baffle counterpart. These observations are consistent with Baird and Rama Rao [3] and Stonestreet [4]. As with the fixed baffle system there is evidence of good radial and axial mixing of uniform intensity.

\section{Heat transfer experiments}

\subsection{Configuration 1: Oscillated fluid}

For the fixed baffle configuration with the oscillated fluid, each experiment was started by ensuring that no air remained in the tube. This was done by means of a bleed valve at the uppermost point in the rig - the top of the curved section joining the two straight limbs - with oil being circulated through the tube by a Connair Churchill heater-pump.

The pistons were then set in motion to provide the desired amplitude and frequency, whilst the heating element in the pump was activated to heat the oil up to 80 ${ }^{\circ} \mathrm{C}$. There was no flow of water in the shells during the heating process. After all three tube-side thermocouples had shown temperatures of $80^{\circ} \mathrm{C}$ for at least $10 \mathrm{~min}$, the oil was taken to be at a steady uniform temperature. At this point, the values at the beginning and end of the $\mathrm{u}$ tube were closed to isolate the oil in the tube, and obtain batch conditions. The mains water supply to each of the cooling process jackets was activated. Finally, the computer data logging program was initiated, at a sampling rate of $1 \mathrm{~Hz}$. These latter processes were performed as quickly as possible, to make the changeover to batch operation as near to instantaneous as possible. The changeover typically lasted between 10 and $20 \mathrm{~s}$. The cooling continued for up to $5 \mathrm{~min}$, after which time the oil temperature, taken as the temperature of the oil at the centre of the tube, was always within $1{ }^{\circ} \mathrm{C}$ of the cooling water temperature. After this time there was very little further change in oil temperature.

Temperature profiles were obtained for a matrix of oscillatory conditions, corresponding to frequencies of $0-10 \mathrm{~Hz}$ in steps of $2 \mathrm{~Hz}$, with amplitudes of 2, 3 and 4 $\mathrm{mm}$ centre to peak. The mains water temperature was typically $15{ }^{\circ} \mathrm{C}$.

The temperature profile obtained at a frequency of 4 $\mathrm{Hz}$ and a $2 \mathrm{~mm}$ centre to peak amplitude is shown in Fig. 6, which is typical of all the temperature profiles. The solid line gives the temperature variation of the oil in the centre of the tube; the temperature of the water at its inlet and outlet is given by the short dashed line and the long dashed line, respectively. As the cooling water flow was started before the data logging program, the water inlet temperature remained constant on the graph. There was, however, some initial variation in the water outlet temperature data. The outlet temperature remained constant for about $20 \mathrm{~s}$ at the temperature to 
Frequency $=4 \mathrm{~Hz}$

Amplitude $=2 \mathrm{~mm}$ centre to peak

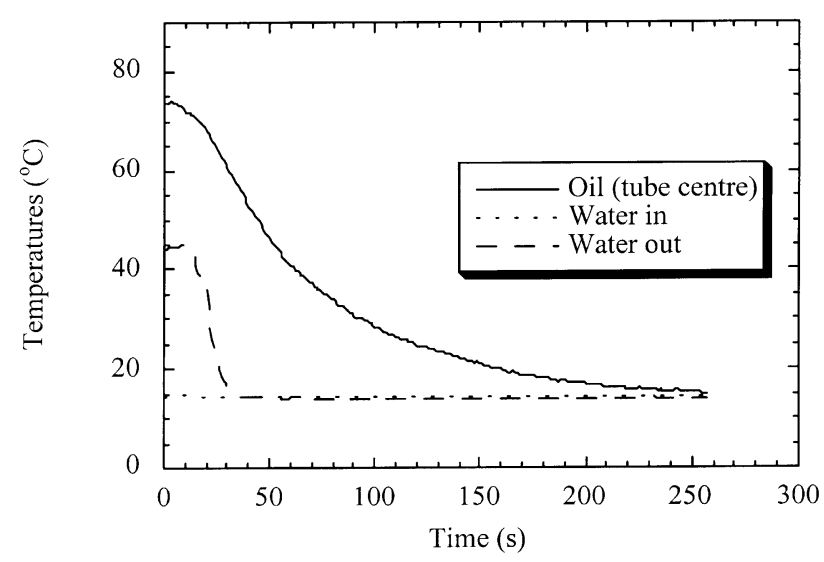

Fig. 6. Configuration 1: Temperature profile, cooling tube-side oil with shell-side mains tap water in the oscillatory flow u-tube.

which it had been heated by the hot oil in the tube. This was the time taken for the cooling water to first reach the outlet. There was then a further $20 \mathrm{~s}$ as the water in the shell cooled before the water inlet and outlet were at the same temperature. Only after this time could the shell-side water be assumed to be at constant temperature.

In order to determine the heat transfer coefficient, the logarithmic graph for this temperature profile was plotted, see Fig. 7. The data did form a straight line for most of the duration of the experiment. However, before about $40 \mathrm{~s}$, when the water temperature was still varying, there was a significant variation from linearity. Also at later times, especially after $200 \mathrm{~s}$, the data became rather noisy. Referring back to Fig. 7, it can be seen that at later times, the temperature difference between the oil and the water was very small, and the rate of change of

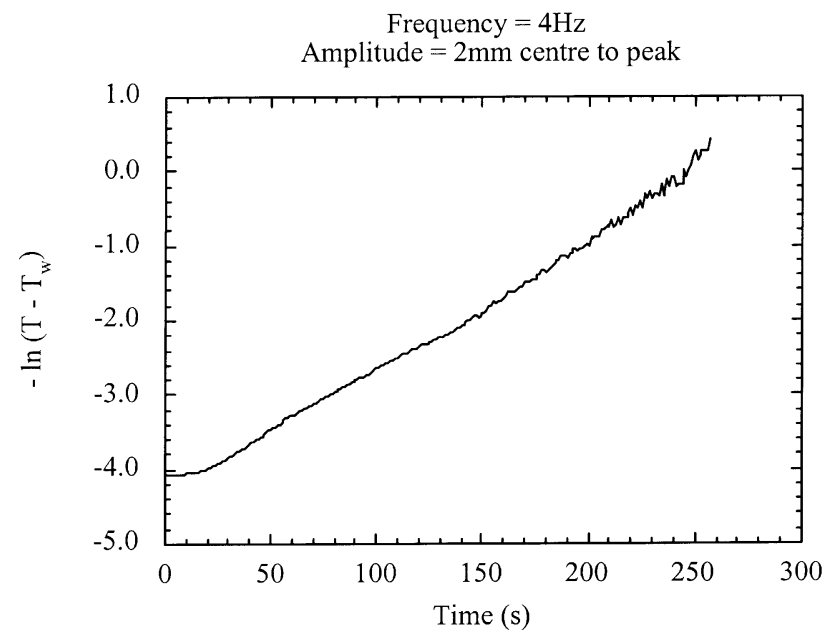

Fig. 7. Configuration 1: The profile of the logarithmic temperature difference between the oil and the water, for the temperature profile shown in Fig. 6. A linear fit is possible between 40 and $150 \mathrm{~s}$. oil temperature was small. With these small temperature differences, the effects of any noise in the data would be magnified. A linear fit can be made over the time interval in which the water temperature was constant and the temperature difference data was noisy. From the slope of this fit the overall heat transfer coefficient is determined to be $163 \mathrm{~W} \mathrm{~m}^{-2} \mathrm{~K}^{-1}$.

Once the shell-side water temperature is steady, the shell-side heat transfer coefficient remains constant at $2000 \mathrm{~W} \mathrm{~m}^{-2} \mathrm{~K}^{-1}$ [4]. This value is independent of the tube-side heat transfer. For the above overall heat transfer coefficient, this gives a tube-side heat transfer coefficient of $178 \mathrm{~W} \mathrm{~m}^{-2} \mathrm{~K}^{-1}$ and a tube-side Nusselt number of 31 .

$N u_{\mathrm{t}}=\frac{h_{\mathrm{t}} D_{\mathrm{i}}}{k_{\mathrm{t}}}=\frac{178 \times 0.024}{0.137}=31$.

At higher oscillatory Reynolds numbers, a problem was caused by the unjacketed curved section of the tube at the top of the vessel, which joins the two straight sections. The oil in this section was not water cooled, and, at oscillatory Reynolds numbers above 300, when the axial dispersion was greater, this oil was dispersed through the oil in the straight sections, retarding the observed rate of cooling. The assumed model of heat transfer was no longer totally accurate at these higher oscillatory Reynolds numbers, and the logarithmic temperature profiles were observed to deviate from linearity, particularly at later times when the warmer oil had dispersed further through the tube. The uncertainty in the straight line fitted to the logarithmic temperature profile therefore increased, which increased the uncertainty in the Nusselt numbers calculated from the slopes of the straight lines for these oscillatory Reynolds numbers. This is shown in Fig. 8, in which $8 \mathrm{~Hz}$ corresponds to an oscillatory Reynolds number of 300 .

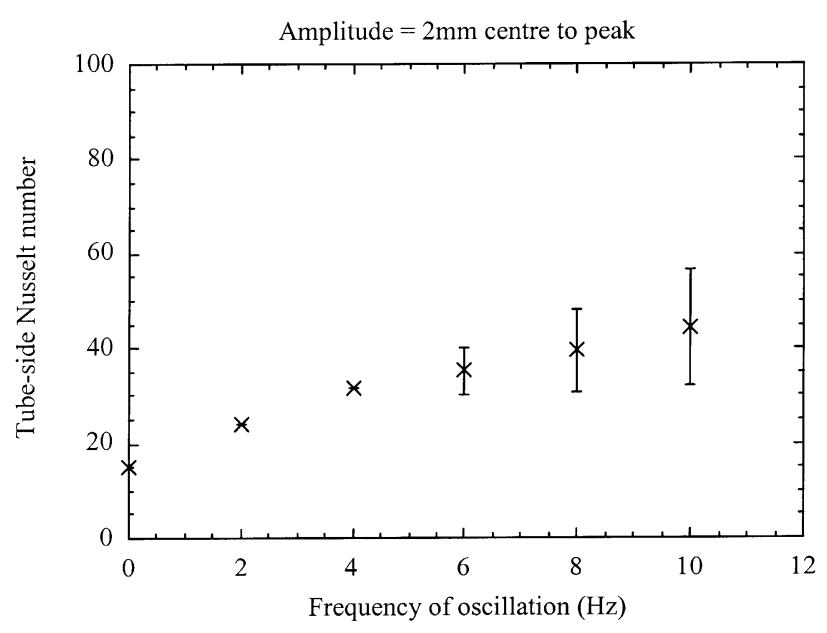

Fig. 8. Configuration 1: A graph of tube-side Nusselt number against the frequency of oscillation for an amplitude of $2 \mathrm{~mm}$ centre to peak in the oscillated fluid u-tube. 
A graph of tube-side Nusselt number against oscillatory Reynolds number is given in Fig. 9 for the three different amplitudes used in these experiments. Considering the cases where oscillation is present, it can be seen from Fig. 9 that the Nusselt number increased significantly with increasing oscillatory Reynolds number, and varying the amplitude at a fixed Reynolds number does not affect the Nusselt number. The tubeside heat transfer coefficient therefore increases with the product of the oscillatory amplitude and frequency the peak oscillatory velocity - rather than the frequency or amplitude individually. Qualitatively, these results are entirely consistent with the results of Mackley and Stonestreet [6]. (An increased scattering of data is visible starting above an oscillatory Reynolds number of 300.)

In the case of no oscillation, a Nusselt number of 13 is obtained. Without oscillations, the presence of baffles is not sufficient to generate the turbulent oscillatory flow mixing nor the efficient radial mixing and temperature uniformity seen in the above cases where oscillation was present. In the absence of any other fluid motion, convection currents will be set up because of the temperature gradients created within the oil. The presence of baffles in a tube is known to improve mixing for low flow rates without oscillation [6], so the convection current flow is modified by the baffles, generating some mixing around the baffles. Hence higher Nusselt numbers are obtained for natural convection in a baffled tube than for natural convection in a smooth wall unbaffled tube. A Nusselt number of 13 is consistent with an extrapolation to zero Reynolds number of the Nusselt number data for steady flow in a baffled tube obtained by Mackley and Stonestreet and presented in Fig. 2 of their paper.

Fig. 10 shows the tube-side Nusselt number data from these experiments on the same graph as the Mackley and Stonestreet [6] data. It can be seen that the

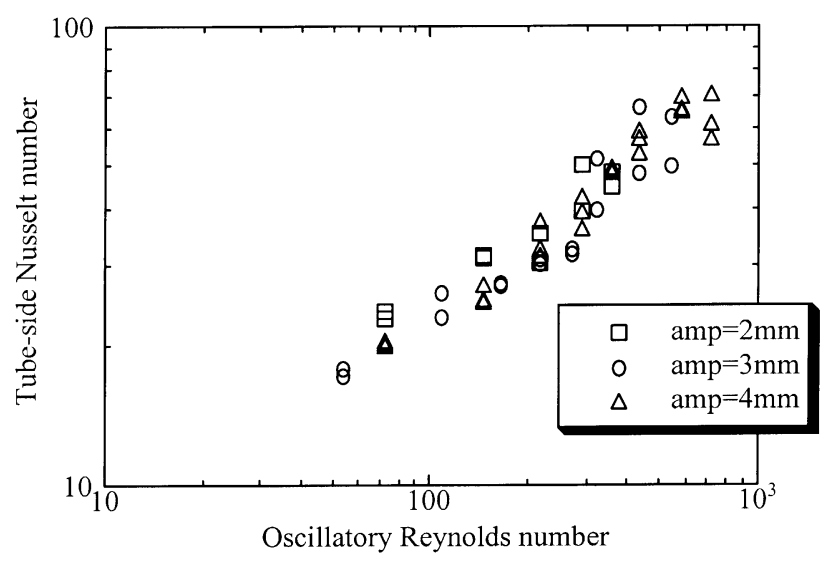

Fig. 9. Configuration 1: A graph of tube-side Nusselt number against the oscillatory Reynolds number for batch heat transfer experiments in the u-tube oscillated fluid apparatus.

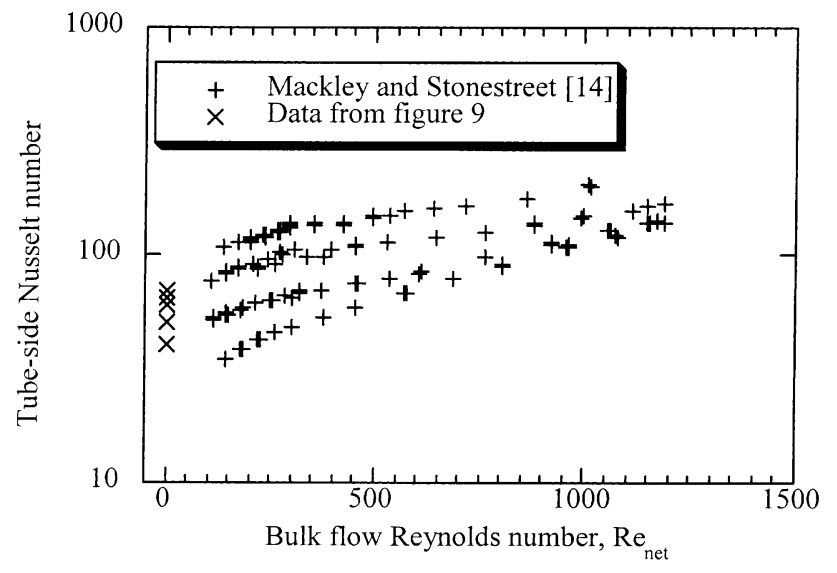

Fig. 10. Configuration 1: A comparison of the batch mode data in Fig. 9 with the continuous mode data of Mackley and Stonestreet [14]. Both sets of data cover oscillatory Reynolds numbers in the range $300-800$.

batch mode data obtained in this work is consistent with an extrapolation of the continuous mode Mackley and Stonestreet [6] data back to zero net flow Reynolds number. Given that Mackely and Stonestreet [6] performed their experiments in a tube of internal diameter of $12 \mathrm{~mm}$, as opposed to $25 \mathrm{~mm}$ in these experiments the agreement between the two sets of data appears good.

\subsection{Configuration 2: Oscillating baffles}

For the oscillating baffle configuration, the experimental procedure was as follows. Each experiment was started when the water and oil had cooled to below 50 ${ }^{\circ} \mathrm{C}$ following the previous experiment. The baffles were then set oscillating at the desired frequency, and the oil was circulated through the shell whilst being heated. Data logging was initiated at a sampling rate of $1 \mathrm{~Hz}$. Heating continued for $4 \mathrm{~min}$, after which time, the oil had reached about $100{ }^{\circ} \mathrm{C}$, and the tube-side water had experienced a temperature increase of the order of 30 ${ }^{\circ} \mathrm{C}$. At this point, the oil cooler was activated to cool the oil and therefore the water in preparation for the following was activated to cool the oil and therefore the water in preparation for the following experiment. Data logging ceased at this point.

Heat transfer measurements were made over a range of oscillatory frequencies from 0 to $8 \mathrm{~Hz}$, increasing in steps of $2 \mathrm{~Hz}$ at a fixed amplitude of $10 \mathrm{~mm}$ centre to peak, corresponding to oscillatory Reynolds numbers varying from 0 to nearly 40,000. The use of a larger range of oscillatory Reynolds numbers than in the fixedbaffles u-tube experiments was due to the higher amplitude, the wider tube $(75 \mathrm{~mm})$ and the lower kinematic viscosity of the process fluid $\left(10^{-6} \mathrm{~m}^{2} \mathrm{~s}^{-1}\right)$, allowing a wider range of oscillatory Reynolds numbers to be explored. 
Several heating and cooling cycles were performed at each oscillatory frequency, but not all data were used in the analysis. Some of the experiments, particularly at the higher frequencies produced temperature differences between the tube axis and wall of less than $0.4{ }^{\circ} \mathrm{C}$. As the resolution of the thermocouple Digitrons and hence the confidence in the temperature readings was 0.1 ${ }^{\circ} \mathrm{C}$, the percentage error in such temperature differences was considered too great for those data to be safely used. Also, with some experiments where the initial water temperature was low, generally the first experiment of each day, the heat flux was so large that the sensor output saturated; these data had to be discarded too. This did not cause problems as each heating cycle created at least 200 data points, and for some conditions, including the no oscillation condition, up to 600 data points were available once the data from several cycles were combined.

Some noise was evident in the data, particularly in the heat flux data, which is not surprising for this type of experiment. The data from each experiment were therefore subjected to an eleven-point smoothing procedure in a spreadsheet package to increase the signal to noise ratio before further analysis. Each point was smoothed by making it the average of itself, the five data points immediately before it and the five data points immediately after it, but retaining the same number of data points overall. In this way, the noise in the data was greatly reduced, but the overall form of the data was preserved, and only one independent data point was lost.

Intermediate experimental data is presented for one of the heating cycles at an oscillatory frequency of $6 \mathrm{~Hz}$. The time evolution of the smoothed heat flux and temperature difference data is shown in Fig. 11. It can be seen that the temperature difference still fluctuates to some extent, but this is largely matched by fluctuations in the measured heat flux. From this data the heat transfer coefficient profile can be determined; this is

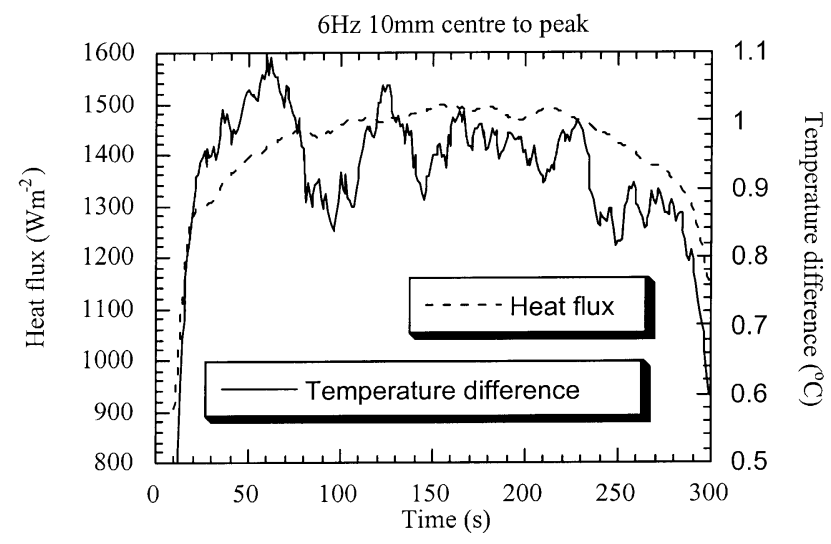

Fig. 11. Configuration 2: The heat flux and tube-side temperature difference profile, heating tube-side water with shell-side oil.
$6 \mathrm{~Hz} 10 \mathrm{~mm}$ centre to peak

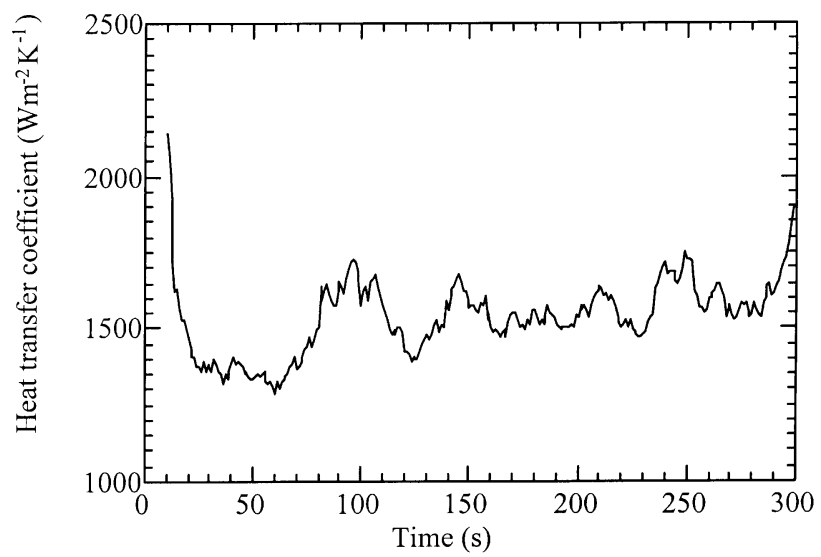

Fig. 12. Configuration 2: The profile of the heat transfer coefficient determined from the data in Fig. 11.

shown in Fig. 12. Some data have been discarded as discussed above. Disregarding the first $20 \mathrm{~s}$, it can be seen that there is still some fluctuation in $h_{\mathrm{t}}$, but there is clearly a mid-point around which the data is oscillating.

For each retained data point a tube side Nusselt number was calculated. A graph of tube side Nusselt number against oscillatory Reynolds number is given in Fig. 13, in which each Nusselt number shown is the mean of at least 200 data points. The confidence limits shown represent the standard deviation of the data points, the confidence in the mean.

It can be seen that there is a significant increase in tube side Nusselt number with increasing oscillatory Reynolds number - an almost ten-fold increase in Nusselt number has been achieved with an oscillatory Reynolds number of 28,000 (6 Hz). (There is a very high degree of uncertainty in the Nusselt number at an

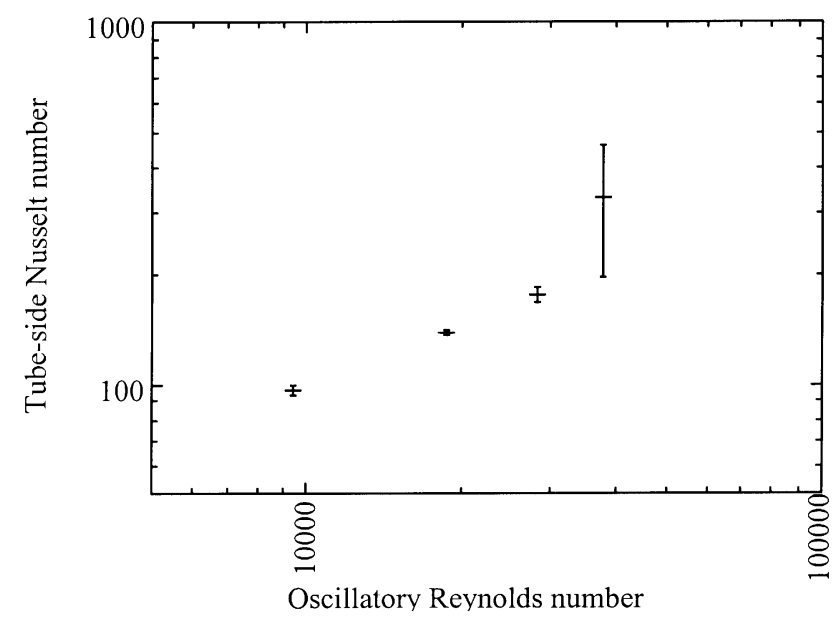

Fig. 13. Configuration 2: A graph of tube-side Nusselt number against the oscillatory Reynolds number for batch heat transfer experiments in the oscillating baffle apparatus, at a centre to peak amplitude of $10 \mathrm{~mm}$. 
oscillatory Reynolds number $38,000(8 \mathrm{~Hz})$. At this frequency the temperature difference was always very low, close to the $0.4{ }^{\circ} \mathrm{C}$ cut-off point. The smoothing procedure could not remove the large fluctuations in the signal received when the actual value contained in the signal was so low.) These data show that high tube-side Nusselt numbers can be achieved with oscillatory flow in this geometry; it is unlikely that the tube-side Nusselt number will limit heat transfer.

Six hundred data points have been used in the determination of the Nusselt number at zero Reynolds number. These are taken from three heating cycles conducted on different days at random times within the other heat transfer experiments. The value of this Nusselt number, between 18 and 20 is consistent with both the data from the u-tube heat transfer experiments $\left(N u_{\mathrm{t}}=13\right)$ and the results of Mackley and Stonestreet [6] extrapolated back to the case of no net flow.

\section{Discussion}

Because of the mechanisms of vortex generation, growth and interaction seen visually in this paper, there are significant radial components to the mixing within each inter-baffle region [2]. These ensure rapid movement of fluid between the tube wall and the rest of the inter-baffle region, permitting the enhanced heat transfer observed in this paper. The intensity of mixing increases with increasing oscillatory Reynolds number, and, as observed in this paper, the tube side Nusselt number also increases with increasing oscillatory Reynolds number.

Fig. 14 shows the final results from both sets of heat transfer experiments, the u-tube experiments and the oscillating baffle experiments, presented on the same axes. Both sets of results show an upward trend with oscillatory Reynolds number and the rate of increase is similar for the two sets of data. However, the ten-fold gap between the two sets of points raises doubts about how much the two sets of data can be compared. The oscillated fluid results and oscillating baffle results were in very different oscillatory Reynolds number regimes. The baffle geometry was also different. The fractional open area of the baffles in the oscillated fluid configuration was twice that in the oscillating baffle configuration, and the oscillating baffle configuration had baffles with three orifices whereas the oscillated fluid configuration had single orifice baffles. $\mathrm{Ni}$ et al. [15] reported that the thickness of a baffle can effect the mixing in oscillatory flow mixing, and the ratio of the baffle thickness to tube diameter differed between the two configurations in this paper. It is possible that when comparing different baffle geometries, that the oscillatory Reynolds number needs to be redefined in terms of the fluid velocity through the baffle and the baffle orifice

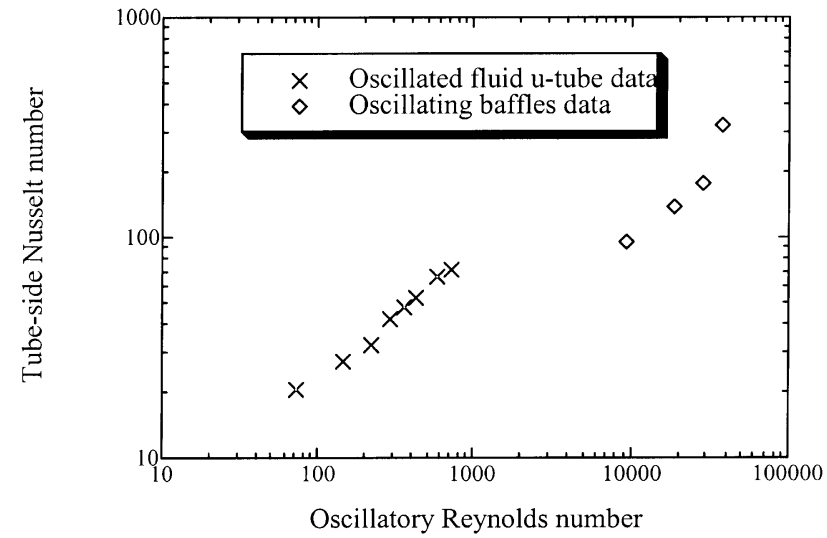

Fig. 14. Both Configurations: The variation of tube-side Nusselt number with oscillatory Reynolds number in batch oscillatory flow. These are the data from both parts of this paper presented together, i.e., the data from the u-tube oscillated fluid experiment and the data from the oscillating baffles experiments.

diameter. Alternatively, further dimensionless groups may need to be considered.

The Nusselt number of 175 , achieved for the oscillatory Reynolds number of 28,000 , is of the same order as would be achieved with a steady turbulent flow in a smooth tube with a net flow Reynolds number of between $10^{4}$ and $10^{5}$. Very high levels of heat transfer are possible with oscillatory flow. Comparisons can also be made with the stirred tank, a widely used mixing vessel, whose applications include batch suspension polymerisations. Correlations for heat transfer in jacketed stirred tanks are reviewed by, for example, Perry [13] and Uhl and Gray [14]. For the case of a tank contents agitated by a flat disc turbine, a typical correlation is given by

$N u_{\text {str }}=K \operatorname{Re}^{2 / 3} \operatorname{Pr}^{1 / 3} \mathrm{Vi}^{0.14}$,

where

$R e_{\text {str }}=\frac{N D_{\text {imp }}^{2}}{v}$,

where $D_{\text {imp }}$ is the impeller diameter and $N$ is the impeller rotational speed. $P r$ is the Prandtl number of the process fluid, defined as $\mu C_{\mathrm{p}} / k$, where $C_{\mathrm{p}}$ is the specific heat capacity and $\mu$ is the dynamic viscosity. $\mathrm{Vi}$ is the ratio of the fluid viscosity at bulk temperature to its viscosity at vessel wall temperature. The constant $K$ is found to fall within the range $0.36-0.74$. On this basis, a Nusselt number of 175 (heat transfer coefficient of $1140 \mathrm{~W} \mathrm{~m}^{-2} \mathrm{~K}^{-1}$ for water in a $0.1 \mathrm{~m}$ diameter tank) can be achieved by a stirred tank, containing water as the process fluid, whose Reynolds number is in the range 2500-7500. For a laboratory scale vessel of impeller diameter $0.03 \mathrm{~m}$, this corresponds to an impeller speed in the range $80-240 \mathrm{rpm}$, a practical operating range. Estimates of the power dissipation in the oscillatory flow mixer under the conditions considered in this paper [7] indicate that it is of the same order as that for a stirred 
tank operating under the conditions discussed above: the heat transfer performance of the oscillatory flow mixer compares acceptably with the stirred tank under the conditions considered.

\section{Practical significance}

Oscillatory flow is a method of mixing using a combination of regularly spaced sharp edges and a periodically reversing flow, which can offer process advantages in both continuous and batch mode. Excellent radial mixing and controllable axial dispersion have already been demonstrated. Previous papers [5,6] have shown that in continuous flow Nusselt numbers more typical of fully turbulent flow can be achieved using oscillatory flow mixing with low net fluid throughput. In batch mode, it is the homogeneity of the mixing throughout the vessel that is important.

The data presented in this paper show that batch oscillatory flow can achieve a good heat transfer performance with an energy efficiency comparable to other conventional mixers, such as turbulent pipe flow or a stirred tank. The heat transfer performance means that both oscillatory flow mixing configurations tested baffle oscillation and fluid oscillation - can be satisfactorily used as batch reactor systems.

\section{Conclusions}

This paper has shown that effective and energy efficient heat transfer can be obtained by oscillatory flow mixing for both the batch fluid oscillation situation and for the batch baffle oscillation, due to the mechanisms of vortex interaction. In both cases the measured heat transfer coefficient depends on the intensity of the oscillation and the general level of heat transfer is comparable to a stirred vessel with similar energy input. The batch heat transfer data obtained for the fluid oscillated case appear to be consistent with previously published data where a net flow through the tube is included.

It can be concluded from the data presented in this paper that the heat transfer performance for both batch oscillatory flow mixing configurations investigated is at least as good as turbulent pipe flow or a stirred vessel thereby indicating that oscillatory flow mixing can at least match conventional heat transfer properties whilst potentially offering additional process advantages in, for example, mixing homogeneity, residence time performance and multiphase processing.

\section{Acknowledgements}

We would like to thank the EPSRC and Zeneca for their support in this project, as well as Professor Keith Carpenter and Dr Paul Stonestreet for their interest and help.

\section{References}

[1] C.R. Brunold, J.C.B. Hunns, M.R. Mackley, J.W. Thompson, Experimental observations on flow patterns and energy losses for oscillatory flow in ducts containing sharp edges, Chem. Eng. Sci. 44 (1989) 1227-1244.

[2] T. Howes, M.R. Mackely, E.P.L. Roberts, The simulation of chaotic mixing and dispersion of periodic flows in baffled channels, Chem. Eng. Sci. 46 (1991) 1669-1677.

[3] M.H.I. Baird, N.V. Rama Rao, Power dissipation and flow patterns in reciprocating baffle-plate columns, Can. J. Chem. Eng. 73 (1995) 417-425.

[4] P. Stonestreet, Department of Chemical Engineering, University of Cambridge, UK, 1995, personal communication.

[5] M.R. Mackley, G.M. Tweddle, I.D. Wyatt, Experimental heat transfer measurements for pulsatile flow in baffled tubes, Chem. Eng. Sci. 45 (1990) 1237-1242.

[6] M.R. Mackley, P. Stonestreet, Heat transfer and associated energy dissipation for oscillatory flow in baffled tubes, Chem. Eng. Sci. 50 (1995) 2211-2224.

[7] G.G. Stephens, Suspension polymerisation in oscillatory flow, $\mathrm{Ph} . \mathrm{D}$. Thesis, Department of Chemical Engineering, University of Cambridge, UK, 1996.

[8] B. Harji, Cambridge Reactor Design Ltd, Cambridge, UK, 1993, personal communication.

[9] P. Mohan, A.N. Emery, T. Al-Hassan, Heat transfer in a mechanically agitated bioreaction vessel, Trans. Inst. Chem. Eng. C 70 (1992) 200-204.

[10] A.D. Jones, N.J. Ward, The use of heat flux sensor in monitoring fouling, Part II Project Report, Department of Chemical Engineering, University of Cambridge, UK, 1994.

[11] T.J. Davies, S.C. Henstridge, Modelling milk fluid fouling, Part II Project Report, Department of Chemical Engineering, University of Cambridge, UK, 1996.

[12] Rhopoint Surface Temperature and Heat Flow Sensors Catalogue and Datasheets, Rhopoint Ltd, Oxted, Surrey, UK, 1992.

[13] R.H. Perry, D. Green, Perry's Chemical Engineers' Handbook, sixth ed., McGraw-Hill, New York, 1984.

[14] V.W. Uhl, J.B. Gray, in: Mixing, Theory and Practice, vol. 1, Academic Press, New York, 1966.

[15] X. Ni, Y. Zhang, I. Mustafa, An investigation of droplet size and droplet size distribution in methylmethacrylate suspension in batch oscillatory-baffled reactor, Chem. Eng. Sci. 53 (1998) 2903-2919. 